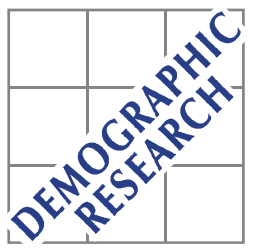

Demographic Research a free, expedited, online journal

of peer-reviewed research and commentary in the population sciences published by the Max Planck Institute for Demographic Research

Konrad-Zuse Str. 1, D-18057 Rostock · GERMANY

www.demographic-research.org

DEMOGRAPHIC RESEARCH

VOLUME 17, ARTICLE 13, PAGES 369-388

PUBLISHED 27 NOVEMBER 2007

http://www.demographic-research.org/Volumes/Vol17/13/

DOI: $10.4054 /$ DemRes.2007.17.13

Research Material

The implications of long term community involvement for the production and circulation of population knowledge

Sangeetha Madhavan, Mark Collinson,

Nicholas W. Townsend, Kathleen Kahn, Stephen M. Tollman

(C) 2007 Madhavan et al.

This open-access work is published under the terms of the Creative Commons Attribution NonCommercial License 2.0 Germany, which permits use, reproduction \& distribution in any medium for non-commercial purposes, provided the original author(s) and source are given credit.

See http:// creativecommons.org/licenses/by-nc/2.0/de/ 


\section{Table of Contents}

1 Introduction $\quad 370$

2 The rationale for a community-based DSS 371

$3 \quad$ History and context of the AHDSS 372

$4 \quad$ AHDSS Site 373

$\begin{array}{lll}5 & \text { The role of fieldworkers } & 374\end{array}$

$\begin{array}{lll}6 & \text { Interactive data collection } & 377\end{array}$

$7 \quad$ Responsibilities to the community 379

$8 \quad$ Conclusion 384

9 Acknowledgements $\quad 385$

$\begin{array}{ll}\text { References } & 386\end{array}$ 


\title{
The implications of long term community involvement for the production and circulation of population knowledge
}

\author{
Sangeetha Madhavan ${ }^{1}$ \\ Mark Collinson ${ }^{2}$ \\ Nicholas W. Townsend ${ }^{3}$ \\ Kathleen Kahn ${ }^{4}$ \\ Stephen M. Tollman ${ }^{5}$
}

\begin{abstract}
Demographic surveillance systems (DSS) depend on community acceptance and involvement to produce high quality longitudinal data. Ensuring community support also exposes power relations usually concealed in the research process. We discuss the Agincourt Health and Demographic Surveillance System in South Africa to argue that: 1) long-term presence and community involvement contribute to high response rates and data quality, 2) to maintain community support the project must demonstrate its usefulness, 3) reporting to community members provides valuable checks on the local relevance and comprehension of questions, and 4) community opinion can modify both wording and content of research questions.
\end{abstract}

\footnotetext{
${ }^{1} \mathrm{PhD}$, Department of African-American Studies and Maryland Population and Research Center, University of Maryland, College Park, Department of Community Health, University of the Witwatersrand. E-mail: smadhava@umd.edu.

${ }^{2}$ MA, MRC/Wits-Agincourt Unit, School of Public Health, University of the Witwatersrand. E-mail: mark@agincourt.co.za

${ }^{3} \mathrm{PhD}$, Department of Anthropology, Brown University. E-mail: Nicholas_Townsend@Brown.edu

${ }^{4}$ DrPH, MRC/Wits-Agincourt Unit, School of Public Health, University of the Witwatersrand.

E-mail: kahnk@sph.wits.ac.za.

${ }^{5}$ MMed, MPH, MA. MRC/Wits-Agincourt Unit, School of Public Health, University of the Witwatersrand.

E-mail: tollmansm@sph.wits.ac.za
} 


\section{Introduction}

The collection of high quality population data has always been of primary concern to demographers because of a dual conviction that such data enable us both to understand population processes and to formulate sensible population and health policies. In subSaharan Africa, the collection of population data has been especially difficult because of a history of association between censuses and taxation and political control, inadequate administrative structures, undeveloped physical infrastructure, low rates of literacy, cultural and linguistic variation, and patterns of belief and behavior that do not accord with the Eurocentric categories of analysis employed by dominant research paradigms. In an effort to gather accurate population data and address major healthrelated issues, several large-scale endeavors have been launched on the continent. Two of the best known of these efforts are the World Fertility Surveys conducted in the 1970s and the continuing rounds of Demographic and Health Surveys. Although we have benefited from the wealth of data that these surveys have generated, the flow of knowledge in them has been in only one direction. In a pattern only too familiar to students of African social and economic history, data has been collected from the populations being studied as raw material, processed by researchers, who are usually not resident in Africa, into findings and results for consumption by first world researchers, and returned by global and, in some cases, national agencies as policy guidelines to local clients.

A demographic surveillance system (DSS) is a long-term, community-based data collection project that provides an alternative to this "neo-colonialist production of knowledge" by involving the population being studied in a more equitable manner through "community involvement." A project's long term involvement with a particular community is simultaneously a mark of its commitment to the principles of decentralization and participation and a guarantee that it will be at least attentive to the concerns of community members. A long term data collection project that fails to involve the community will not be able to produce high-quality data. Conversely, a project that takes community involvement seriously is likely to produce data that is internally consistent, accurate in reflecting local processes, and relevant to the people being studied.

The Agincourt Health and Demographic Surveillance System (AHDSS) is situated in a poor, rural area of South Africa's Mpumalanga Province. The AHDSS shares with other demographic surveillance projects three characteristics with profound implications for the production and circulation of population knowledge: 1) long term presence in the community, 2) the primary purpose of improving the provision of local health services, and 3) commitment to community involvement as a matter of principle as well as of pragmatic utility (das Gupta et al 1997; Kahn and Tollman 1998). Through 
a description of the history and design of the AHDSS we indicate some of the implications of these features for data quality, the kinds of information collected, and the resulting circulation of knowledge. We use "knowledge" broadly and variously to encompass local knowledge, policy recommendations, intervention programs, and the definition of problems, as well as demographically recognizable data. We conclude that the DSS approach makes specific and important contributions to demographic data and research, and that it also raises and confronts (though it does not resolve) issues of power in the production of knowledge and policy that are frequently made invisible by other approaches to research.

\section{The rationale for a community-based DSS}

One of the main objectives of the DSS is to empower people with population knowledge that they can use to improve their physical, emotional, and mental wellbeing. Empowerement of this sort is a partial response to the critique of health promotion (Lupton 1999) that has asked 1) what does it means to be healthy? and 2) who sets agendas about health promotion? While experts may have the best of intentions, they fail to recognize that the people whose behaviour they are trying to change might not share the same perception of these risks. Similar critiques of development policy more generally have argued that the external identification of deficits and needs may blind development agents to the existence of community assets that are vital for the survival and well-being of community members and are essential foundations for development projects (Kretzman and McKnight 1993; Moser 1993).

The proponents for community involvement have been concerned with reversing or at least altering the flows of learning and of power (Chambers 1996) by encouraging researchers to learn from the community and to give those being researched the genuine opportunity to define their own perceptions of problems and descriptions of their situations. This is crucially important in the developing world where respondents, particuarly women, have very little power or voice in determining research agendas. In a more participatory approach, respondents are seen as "agents of and not as victims of knowledge" (Jackson and van Vlaenderen 1994:9) and as "co-producers of the knowledge generated in the research" (Macleod et al. 1998: 215). Long-term presence and a clear service delivery component have been seen as essential for building rapport with the local residents and ensuring cooperation and community involvement (Taylor 1997).

The attempt to incorporate community definitions into research and policy has been accompanied by an attempt to empower communities to take responsibility for their own well-being, for it is recognized that if definitions of good health and risk are 
constructed by external actors then responsibility for health promotion will also be seen as belonging to those actors who will be expected to design and implement health promotion strategies (Eisenberg 1987). However, this attempt has its own problems. In a critical examination of development programs in South Africa, Emmett contends that while the concept of "community participation" has been incorporated into a wide range of government and NGO policies and programs the practice of development has an inadequate theory of community (Emmett 2000:502). Emmett argues that the rhetoric of community involvment obscures conflicting interests within communities, the lack of resources of poor communities, and the fact that communities are embedded in larger structures which create many of their problems and provide the arena within which they must operate to solve those problems. The DSS, while not resolving these issues, promotes greater transparency of these issues and therefore, offers more scope for addressing them in a meaningful manner. It should be noted that anthropologists working in the area (cf. Niehaus 2001) have been particularly useful in identifying points of division within and across communities.

\section{History and context of the AHDSS}

The AHDSS is a key component of the Agincourt Health and Population Unit (AHPU) ${ }^{6}$. The AHPU, like other programs around the world, builds on South African precedent as well as internationally shared interests and experiences. The Pholela Health Center was established in Northern Natal in 1940 on the basis of a children's nutritional survey, which showed that many of their prevalent diseases were preventable with better nutrition (Tollman et al. 1997). The orientation of the Pholela Health Center was based on a working principle that "new concepts and practices should never be imposed upon the community; rather, they should be integrated into the culture through active popular participation" (Tollman et al. 1997:21). This was in direct contrast to state policy, which ensured that all information and policies came from the government with little or no participation of black Africans. Population data, for example, were not only collected and disseminated by the white powers but were also manipulated to show population figures that supported existing policies of racial segregation. Accompanying the dismantling of apartheid and the beginning of a long-term process of transformation of the country, as a whole, was a need to fully involve rural black communities in

\footnotetext{
${ }^{6}$ Since 2002 the Agincourt Health and Population Unit was has been known formally as the Medical Research Council/University of the Witwatersrand Agincourt Unit in Rural Public Health and Health Transitions Research (MRC/WITS Agincourt Unit) http://web.wits.ac.za/Academic/Health/PublicHealth/Agincourt/agincourthome.htm
} 
development programs. The AHPU and the AHDSS were initiated, in part, to meet this need.

\section{AHDSS Site}

The AHDSS is situated in a rural area that was, under apartheid, part of the "homeland" system of segregation of the black population. The homeland areas were not economically self-sufficient but housed a labor reserve for white-owned mines and farms and, more recently, for industries (Spiegel 1987). Since the end of apartheid, legal restrictions on movement and residence have been abolished, but labor migration remains central to the economic strategies of the people of the study area. There is one health center and five satellite clinics to serve an area of about 400 square kilometers. Hospitals continue to experience a shortage of basic supplies and a steady presence of qualified doctors. Most villages have primary schools but not many have secondary schools. Schools in the area suffer from underpaid teachers, lack of supplies, and high dropout rates. The water supply continues to be a serious problem in many villages. Ethnic identities include Tsonga, Pedi, Tswana, Sotho, and Zulu though everyone speaks Tsonga. The border between South Africa and Mozambique has always been porous and the complex and changing pattern of ethnic identification in the region cuts across national and internal borders (Ramutsindela and Simon 1999).

The site has hosted community health projects and social science research for over twenty years (Tollman et al.1995). The site was originally chosen because: 1) the location was a substantial distance from any tar road and service delivery was extremely limited; 2) the sub-district had an existing health center, and; 3) the population included a large number of Mozambicans displaced from the civil war in that country. The AHDSS has been conducting an annual census of the entire population since 1992. Aside from standard information on age, gender, educational attainment and marital status, the census provides information on migrant and refugee status as well as household relationships. In addition, the data include information on births, deaths and migration, complete fertility histories for each woman, and verbal autopsies ${ }^{7}$.

The black population of approximately 70,000 people, dispersed over twenty three villages, has a low level of education and high rates of unemployment, labor migration,

\footnotetext{
${ }^{7}$ A verbal autopsy (VA) is a structured in-depth interview that is administered to the next of kin to the deceased to elicit detailed information on the circumstances of the death. The responses are then assesesed by two physicians who assign a cause of death. In contexts where people do not necessarily die in the hospital, the VA serves as a satisfactory means to ascertain cause of death. A team of fieldworkers have been specially trained to carry out this task in a manner that protects the families' need for privacy and grieving.
} 
and substantial population movement to and from neighboring Mozambique. Analysis of the census conducted in 1992 provided some basic demographic descriptions of the population and identified important health issues. The population had a large percentage of people under the age of 15 and a small percentage of elderly. Fertility in the AHPU site underwent dramatic decline in the 1980s and 1990s, from a TFR of about 6 to 2.8 in 2001. Despite this drop, adolescent fertility remains high, with almost $40 \%$ of 19 year olds having had at least one child (Garenne et al. 2000). This finding has spurred vigorous efforts to institute a reproductive health and life skills education program in the schools. Mortality steadily worsened over the period 1992-2000 from a life expectancy at birth of 71.8 years down to 63.5 for women, and 66.1 to 59.8 for men (Tollman et al. 1999). Much of the decline can be attributed to an increase in HIV/AIDS related mortality after 1996. In the $1998-2000$ period, mortality in children under-5 was 56/1000 compared with 31/1000 in 1992-1994 and HIV/AIDS was the number one cause of death (Tollman et al. 2001). More recent data show further declines in life expectancy and an increase in HIV/AIDS related mortality.

The main constituency of the AHDSS is health policymakers, planners and researchers at the district, national and international levels. It also faces the challenge of continuously convincing skeptical funders about the intrinsic value of the project. The tension between the goals of empowering the local community and of informing external development agents does not necessarily result in contradiction, but the multiple objectives of the AHDSS, which are shared by DSS projects generally, complicates the flow of knowledge. The coordination of these different goals in the context of a DSS structure has direct implications for the kind and quality of knowledge produced and for the direction and intensity of its circulation. We explore these implications by considering: 1) the role of fieldworkers; 2) the interactive process through which data collection is modified; 3 ) the responsibilities to the community.

\section{The role of fieldworkers}

The importance of fieldworkers in the maintenance of a DSS has been described by das Gupta et al. (1997). However, the critical role of fieldworkers in the construction and transmission of ideas on particular topics in the AHDSS deserves discussion. Because all the interviewers are members of the community they are intimately familiar with the way in which the residents of these villages think about health issues. For example, the role of witchcraft in causing illness is not necessarily appreciated by an outsider but the interviwers can not only understand this construction of illness but can also incorporate it into interpreting responses to research questions. Therefore, the role of social conflict, which often sets the background for witchcraft accusations, would now enter the 
context of understanding a particular death event or episode of disease. The local fieldworkers are able to incorporate discussion of occult forces into the interview in a way that does not deny local realities nor obscure the medical information relevant to the physicians.

Weekly meetings between management and the field staff provide an opportunity to discuss particular issues and the construction of questions. For example, the question "where does person x live?" is usually seen as a fairly value-free, straightforward issue but turns out to be highly contested in southern Africa. In the Agincourt area, as in many other areas in South Africa, people do not identify with only one residence. The intensity of mobility combined with the fluidity of households make it very difficult for either fieldworkers or respondents to determine 1) who is a migrant and 2) whether he/she has moved temporarily or permanently. In an effort to improve the measurement of mobility and inter-household connections, the DSS has initiated a migration reconciliation project to match immigrants and out migrants within the field site. Similar issues can be found with questions about fertility, in which researchers expect a clear-cut distinction between biological and social parenthood that may not correspond to local perspectives (Townsend 1997). Whereas the census, by its very nature, needs to have discrete categories, people's lives tend to be fluid and hard to classify. The AHDSS fieldworkers recognize this complexity and have developed a consistent recording and cross checking system based on extensive dialogue.

Language translation and differences in cultural understandings always make knowledge transfer complicated, but the long term presence of a DSS project can help overcome some of the barriers. To being with, all the fieldworkers are fluent in Tsonga which is spoken by everyone regardless of ethnicity. The AHDSS devotes a substantial amount of time to ensuring proper translation of questions, an investment in situational specificity that is easily justified because of the long-term presence in one place. Translation in this sense is more than a mechanistic process of deciding which wording is best; discussion continues until the fieldworkers understand the sense of a question and reach an agreement on its translation. Concepts such as "household," "headship," and "kin," which are fraught with conceptual difficulties in English, need much time and effort to make sure that fieldworkers 1) understand the meaning and 2) are able to convey the meaning in Tsonga to respondents. For example, the Tsonga word, muti, refers to both family and household whereas the word ndyangu refers to the extended family. Given that "household" is defined by the AHDSS as a residential unit with "members who eat together out of the same pot," it is essential that fieldworkers use the term muti and provide a clear explanation of what they are looking for.

While the long-term study allows fieldworkers to develop experience and skill, it also establishes routines which can become monotonous and can diminish their enthusiasm and concentration. It is for this reason that the program management 
involves fieldworkers in as many other affiliated projects as possible in order to expose them to other techniques and open up more opportunities for dialogue and knowledge exchange. The fieldworkers are also encouraged and supported, where possible, to diversify their skills through coursework and academic training. While this contributes to the AHDSS goal of contributing to local capacity and individual lievelihoods, it also has the negative consequence for the AHDSS of the loss of the most skilled fieldworkers for better opportunities. The exclusive employment of local fieldworkers has become a great strength of the Agincourt project, but it was not an integral part of the original design.

In fact, the importance of employing local fieldworkers was impressed on the project's designers during consultation with community members. These initial discussions were the occasion for the exchange of hopes and concerns, and it was the expression of local awareness of barriers to research that led to a modification of the research approach. Initial meetings with community leaders raised concerns about privacy and outside interference and made it clear that the relationship of the fieldworkers to the community was as important to data quality as their formal qualifications. In collaboration with community leaders, church members, school officials, health sector personnel and other community organizations, a system was devised where each leader would nominate two young people from their community, selected for their intelligence and with a stipulated minimum education, to be interviewed by the project managers. Eventually all field staff were recruited from these local nominees and a precedent was established that no field staff would be employed from outside the sub-district.

This reciprocal communication of interests has worked well in creating a research team able to serve both the research interests of the project and the interests of the community in controlling access, but it has not been without problems. It has been important for the AHDSS to insist on educational standards and aptitude among the nominees in order to maintain an effective data collection procedure. It has also been crucial to obtain a broad range of nominations to prevent the research project being simply a source of patronage to entrenched local leaders. Administrative, economic, religious, political, and educational qualifications all may be translated into claims to leadership status, and diverse interests within the community mean that any consultation of "community leaders" must include a wide range of people. In addition, any reference to leaders must be sensitive to ongoing power struggles between the traditional leadership represented by chiefs and village headmen and newly emerging political leadership from the Reconstruction and Development Committees, which are a product of the country's movement to a democratic system of governance. The process of selecting from among nominees has also had to be explained and justified and seen to be transparent so that those whose nominees are rejected do not take offence. There 
have been objections when nominees have been rejected, and the system as a whole has to be monitored to ensure that individual disappointment does not translate into rejection of the project.

While the benefits of locally base fieldworkers are clear, it is precisely their embeddedness in community life that also poses certain challenges to rapport building and knowledge exchange. One, people may be reluctant to reveal sensitive information to someone they know very well particularly if this person has a kinship connection. Related to this is the issue of fieldworkers presuming knowledge about people and households without direct inquiry. Both these issues have been addressed by 1) not assigning a fieldworker to his/her home village and 2) encouraging the fieldworkers to recuse themselves from particular households or even villages if they are not comfortable working there. Two, because they are members of the community, the fieldworkers themselves, are also affected by witchcraft accusations. During the 2001 census update there was a spate of witchcraft accusations made by the youth in one particular village. The fieldworkers from that village were extremely reluctant to work there for fear that they would be implicated in these conflicts. In this case, familiarity with the situation became an obstacle to effective data collection, but local knowledge alerted the project to the potential problem before either fieldworkers were put at risk or superficial data collection was carried out. Three, existing relationships between fieldworkers and community members might influence the way in which fieldworkers convey concerns expressed by respondents. For example, if someone complains about research fatigue (as people inevitably do), fieldworkers may not convey this to other project staff for fear of losing their job. Finally, because the fieldworkers quite often know each other outside the DSS context, they face the awkward situation of competing with their friends for promotions and other rewards. Every effort is made to ensure confidentiality of individual fieldworker records and to promote a collaborative learning environment in which peers are seen as vital resources for individual advancement.

\section{Interactive data collection}

A unique feature of demographic surveillance systems is that they are long-term, which can enable an evolution or maturing of relationships between the project staff and community members. When a new research project is started the site manager uses established channels of communication to keep people informed, especially people who will be fielding questions from community members. The village governing body is the Reconstruction and Development Committee, comprising an elected chair, the induna (traditional leader), and representatives from key village structures. Members of these committees are visited two or three times a year by project staff, usually at the onset of 
a new piece of fieldwork, and at least once preceding the annual census round. This dialogue provides a way for community residents to voice their thoughts about the data collection effort. For example, should residents find certain questions on the census objectionable, they have a channel through which they can voice their grievances. The importance of this communication cannot be stressed enough as it determines the success of the DSS.

The design of a DSS contributes to data of a high quality in the sense that inconsistencies, non-response, missing data, and misunderstood questions are minimized. The DSS design also modifies the kind of data collected. The questions to be asked, and thus the data to be collected originate with the researchers, but these questions have been modified by two forms of community influence: the direct experience of the researchers in the community and the explicit reaction of community members expressed in a series of interactions over time. The researchers who started the data collection project had worked for years in the community on primary health care organization and delivery and held many community meetings to explain the process and its purposes. The original set of questions was developed by the management staff in consultation with local health practitioners and members of the field team. In the case of Agincourt, virtually the entire staff has spent substantial periods of time in the fieldsite and are, therefore, in a position to construct locally meaningful questions. The questions are constantly reviewed at every round based on experiences from the previous round and from suggestions from members of the management and field teams. For example, if a particular question causes notable anxiety for respondents, it might be deleted or at least modified for the next round. This form of community involvement can be seen as a compromise of research design in that it limits the power of the research team to impose an agenda or set of problem definitions on the community. However it also minimizes the likelihood that apparently reasonable questions may come up with invalid results.

The labor form, a recent addition to the census, was designed to measure labor force participation and economic activity in the community. It was piloted extensively, and discussed amongst members of the field team and management staff before it was administered. The fieldworkers played an important role in determining the categories used and the kinds of economic activity specified. Even the definition of work was modified after careful discussion with field teams. For example, while researchers considered subsistence farming to be a work category, fieldworkers insisted that respondents would not consider it work since there were no resources coming into the family from outside. The local identification of "work" as activity that generates new resources differed from one that sees subsistence production as work also. The researchers did not have to abandon their definition, since they could ask several questions and aggregate the answers. But they did have to refine their own concepts to 
clarify their intention and capture local distinctions. In the process, their understanding of the significance of employment in local social relationships was also altered. Another project currently underway that is heavily based in local knowledge is the use of in-depth ethnographic data from a study on social connections and children's wellbeing (Townsend et al. 2006) to develop improved measures of social conneciton in the DSS. The strength of inductive qualitative analysis lies in the fact that the identified indictors are conceptually grounded in people's lived experience rather than externally generated categories.

\section{Responsibilities to the community}

In a community-based project, the phases of instrument design, data collection, and dissemination of findings are not distinct in time or restricted to particular occasions. For the first two, the quality and kind of data is affected by multiple interactions, but the direction of the flow of information is essentially from the community to the researchers. In the dissemination aspect of the project, the flow is ostensibly reversed, but even here the interaction is marked, and the distinction between data collection and knowledge dissemination is itself blurred.

For example, when conducting a verbal autopsy and collecting a treatment history, caretakers often report that they used indigenous medicines in their first attempt at treatment, followed by western biomedicine when the patient did not recover. Field interviewers are instructed not to make any value judgment on people's choice of health care but they are also obligated to refer sick patients to clinics if they judge that to be appropriate and necessary. While negotiating these potentially competing concerns with unbiased data collection and direct intervention, the interviewers are simultaneously contributing to the community discussion about what constitutes appropriate health care and treatment. The great advantage of the DSS over a single survey or intervention is that this contribution is not simply the interjection of "knowledge" controlled by one party. On the contrary, both the DSS fieldworkers and the community members constantly reexamine and refine the knowledge they exchange as participants in a dynamic social process.

More direct dissemination of knowledge to the community has taken the form of health promotion, including pamphlets, health talks, and the training of nurses to conduct the health promotion interventions. The source of the knowledge embedded in these inputs has been AHDSS research and external sources reviewed by senior public health academics in the Program. The impact of these interventions on health practices is difficult to assess. Exchanges of knowledge do not, in themselves, change behavior. Knowledge about the transmission of HIV, for instance, has been disseminated in the 
Agincourt community and in communities around the world with variable impact on behavior. Conversely, local knowledge that access to health services is restricted by the hours that clinics are open may be passed to the personel of those clinics with no impact on operating schedules. Knowledge, clearly, is only one element in the mix of factors determining practice, but dissemination at least makes knowledge available to community members and contributes to the community's repertoire of knowledge.

Health promotion is certainly a transmission of knowledge within the context of the DSS, and an important goal of the AHDSS, as a whole, but it is not integral to the DSS itself. Research feedback, on the other hand, is an essential element of the DSS design, and itself often leads to the transmission of health promotion information, particularly when dialogue occurs between community members and project staff during feedback sessions. The feedback sessions are village meetings where research findings are presented and discussed. Generally, posters that highlight health and population issues as revealed by the census are made for each village. For example, a poster that included an unemployment rate of 59\% along with number of people, number of births and number of in-migrants generated a discussion about the scarcity of jobs and possible responses. These meetings provide the opportunity for people to engage with the project, discuss issues that arise from the information, or from project operations, or general problems encountered in the area. It should be noted that the number and composition of the attendees at these meetings and at other research feedback sessions that have been held in the area vary greatly from village to village (Macleod et al. 1998). So while these meetings are open to the entire community, they are not necessarily meetings of the whole community underscoring the important role of stratification within a community. There is also some concern that Reconstruction and Development Committee (RDC) members who often attend such meetings do not provide a sufficient representation of the whole community. It is for this reason that project staff make every effort to reach out to other community leaders such as traditional chiefs, teachers, church leaders, etc. who may each have differing interests and different consituencies.

What is important about these forums is that they allow community members to voice their priorities, which may, in some instances, differ from those identified by the project. While it is rare for community members to question any of the data directly, they may not agree with the conclusions to be drawn from the data. For example, the negative aspects of "population growth" are confronted by a local sense of the danger of "losing people" from increasing numbers of AIDS related deaths, and community members do not uniformly agree that teenage pregnancy is a health or social "problem." In some cases, research findings occasion discussions that reveal dissent within the community. Reports on the nutritional status of women and infatnts, for instance, occasioned discussion about the taboo around women eating eggs and cheese. While 
older people asserted that consumption of these foods is linked to promiscuity, others challenged them and pointed out that they can enhance people's health. In such cases, the goal is not to achieve total consensus but rather to provide an opportunity for various voices, including that of the project, to be heard and let individuals decide what they should and should not do. In other cicumstances, however, people agree with research conclusions. The identification of stroke and chronic diseases, for example, has resonated at meetings, helping to bring a general but unarticulated concern into the realm of public recognition. The main point is that the success of any intervention depends on the community's recognition of the problem, and on the intervention agents knowing how people think about health and well-being.

Besides the feedback meetings on research results, knowledge is ciruclated to communities through village 'fact sheets'. These are pamphlets that provide villagespecific information on population dynamics (numbers of in- and out-migrants, births and deaths), population size in different categories (e.g. children of school-going age) and major causes of death. These fact sheets are updated annually and distributed to community leaders. They are also available to any community member on request. Community members and leaders use this information primarily to advocate for improved services or to initiate projects by identifying and describing the target population for the proposed project. For example, the Reconstruction and Development Committee in one village used information from the fact sheet in a successful proposal to an NGO to fund strategic planning in the community. Where the exact information needed is not available on fact sheets, a query is run on the DSS database. For a fundraising initiative to establish a photo-journalism interest group, a query was run to tabulate the number of youth by sex in several villages in order to guage the potential interest. Similarly, a woman's group asked for the number of children aged 2-5 residing in the village in order to write a funding proposal for a creche.

Measuring the impact of any intervention in South Africa, including the AHDSS, is complicated by that fact that an entire social transformation has been in progress for the past 10 years. Every sector of society including health has changed both positively and negatively making it extremely difficult to isolate the effects of any one intervention. In addition, it is likely that the presence of a long term research program can, in itself, alter the ways in which people think and behave through the production and circulation of knowledge. However, it should be noted that one of the goals of the AHDSS is empowerment through knowledge that has been generated through strong community participation. Where communities are active participants in the process of data collection, dissemination and identifying problems, there is likely to be a greater ownership of the knowledge produced. While it is difficult to say whether this has actually happened, both the longevity of the project and the uses of the data reflect a certain amount of community commitment to the maintenance of the AHDSS. 
One issue that community leaders raised repeatedly in the initial community discussions was the need to see a direct benefit to the community arising from the project's activities. This was usually expressed as a request for something concrete such as a new health centre or clinic. While program leaders were aware that a contribution on this scale this was never likely to be within their reach, there were several improvements in the health services that they could achieve. These became an important part of the informal contract that emerged. The presence of the project has enabled improved laboratory services such as blood testing to be put in place, has led to improved staff training and ambulance service, and to the establishment of adolescent health clinics (Tollman, Herbst, and Garenne 1995).

Health systems improvement is primarily inititiated by senior public health academics guided by their own expreience and informed by research. AHDSS related research has contributed directly to specific interventions in cases where an understanding of a problem has deepened, or an intervention has been developed and tested in the sub-district. Examples to date include the management of sexually transmitted diseases (including HIV/AIDS) and respiratory infections. In both these cases, a more systematic protocol was put into place based on needs identified through research. With the former, the program is still attempting to reach out to more young people, many of whom are reluctant to seek services. In addition, some leading members of the community such as school principals and church leaders are still hesitant to give their full support especially to contentious interventions such as condom distribution. However, the recruitment of peer counsellors from the communities is a positive step in this endeavor. New projects will explore the management of childhood malnutrition, and chronic diseases in older adults. In all these cases, the interventions are directed at the community but their implementation and design has been informed by both knowledge about the community derived from the AHDSS and the knowledge about social dynamics that is uncovered at every stage of the process.

The use of AHDSS data to inform policy has been limited thus far but there are some notable exceptions. The African National Congress (ANC) office in one village requested fact sheets for 14 villages to inform its plan for ward demarcation. Another ANC office requested information on 5 villages to inform strategic upgrading of water reticulation services. The sub-district health center has requested information on 10 villages in order to update their records on catchment areas. Finally, Farm AID rural community development services have asked for data on 5 villages under consideration for farm aid projects. These accomplishments are fairly modest given the enormous challenges facing policymakers in their attempts to rectify the deep structural inequalities that have its roots in apartheid but continue till today. Indeed one can ask to what extent the DSS addresses any of these broader issues of socioeconomic 
inequalities and justice. Whereas tangible evidence of improvements in equity is hard to come by, it is fair to say that the work of the AHPU is firmly anchored in the health transition underway in the country. Every effort is made to be responsive to new findings, new intervention approaches and new solutions. For example, once it was clear that the uptake of poverty alleviation grants nationally could be vastly improved, the DSS responded by 1) collecting data on grants and 2) strengthening existing social services to identify people in need. In the wake of the government roll-out of antiretroviral drugs for HIV infected people, the DSS is examining ways to incorporate clinic use data in order to monitor the uptake of ARTs. It should be noted that the site is also being prepared for vaccine trials. None of these efforts will succeed without community participation. Finally, the presence of the DSS and the increasing numbers of academics and funders involved with the project certainly increases the exposure of an area of South Africa that was and continues to be marginalized.

Once the AHDSS data is distributed to the community it becomes a resource for a variety of interests and groups. However, the AHDSS does not play a role in initiating or running community-based projects. However, project staff are also well aware that using information and initiating development projects are easier said than done, especially for people with limited education and who are marginalized in numerous ways. As a result, a full-time liason person has been put in place to assist community members in using the information to write proposals and initiate development projects. In addition, the program is considering the possibility of running fund-raising and proposal-development workshops, and training sessions on financial mangement and fund governance. The AHDSS, like any community-based organization, faces limitations on its resources and has to determine how to allocate those resources so as not to overload research staff with community development commitments. More importantly, the program must not raise false expectations of what it can deliver. Once again, the circulation of different forms of knowledge is complex and interactive, with data collected from the community being disseminated and used in ways which require other kinds of knowledge to make them effective.

One very serious issue that the AHDSS has had to address is confidentiality. Unlike national surveys using a representative sample, the DSS is focused on a well defined geographic area with a clearly enumerated population. Therefore, the risk of being treated differently for residents of the fieldsite can become a serious issue. Furthermore, the long term relationships that field staff develop with community members does carry a certain amount of risk of exposure through unintended slips of the tongue. Being identified with an area that has an increasing HIV prevalence could lead to negative reactions towards community members. While it is clear that no system is fullproof including national surveys and censuses, there are certain precautions that can be taken to mimimize the risk of exposure. One, even though the AHDSS has been 
operating for over 10 years, all community members have the right to decline participation in the census or any other study. Two, the AHDSS management devotes a substantial amount of time training the fieldworkers on confidentiality and consent. Three, when any part of the data is given to researchers for analysis, only the minimum number of identifiers needed for the analysis are included in the dataset. Four, all satellite projects are required to attain IRB clearance from both South African and international institutions. In short, it is obvious to everyone involved with the AHDSS that even one breach of confidentiality can jeopardize the continuation of the AHDSS.

\section{Conclusion}

We argue that while the DSS design does allow production and circulation of population knowledge that is applicable to practical innovations and interventions, the greatest value of this knowledge is its potential to inform theory and research practice. The DSS design makes three particularly significant contributions. First, because data collection is repeated and continuing, checking and re-checking allows for the resolution of inconsistencies and the follow-up of missing data. Second, repeated data collection on the same population allows not only monitoring of trends but also description of sequences of events in time and causal modeling. Third, and perhaps most important, the discussion and review of questions and responses in an iteration or cycling between community members, members of the research team, and fieldworkers from the community modifies the population data that is produced. Community involvement at this level means that the population knowledge derived from a DSS can be framed in terms of categories that are relevant to the people whose lives are the objects of investigation. Meaningful categorization of population processes rather than the imposition of global constructs is a crucial step to meaningful analyses. Since the categories used by the DSS can be designed to be reduced to standard categories, the knowledge produced by a DSS can meet the sometimes contradictory requirements of situational specificity and comparability.

Our discussion about about the value of DSS systems in knowledge production would be incomplete without some mention about resource limitations. Long-term studies are very resource intensive, in money, time and labor (Caldwell and Caldwell 1992) so one of the issues for funders is whether they are getting their "money's worth" in terms of data. The calculus of value is complicated by the different trajectories of

results of more traditional survey based methods and a community based longitudinal system. Whereas one time surveys are effective in providing quick descriptive results and some limited analytical possibilities for certain issues of interest (e.g. knowledge about HIV among adolescents), the value of the DSS is cumulative, so that the results 
are not immediate. Das Gupta et al. (1997) estimate that a minimum of 100,000 person years of data is necessary for adequate demographic analysis. Furthermore, there is question as to the localized nature of DSS systems. In other words, to what extent do findings from intensive data collection in such a small area help in addressing problems on a national scale? The most compelling argument to fund DSS sites is that longitudinal data are essential if we want to 1) establish causality, 2) examine trends over time and 3) evaluate the effectiveness of interventions. This has particular salience in South Africa where there is an urgent need to monitor the effectiveness of antiretroviral therapy rollout on incidence and prevalence of HIV. However, maintaining the funding of a DSS raises problems even when the intrinsic value of the enterprise is acknowledged. DSS funding has to be continuous, for the next round of data collection cannot be postponed, and is susceptible to the changing focus of funders and foundations that do not want to commit their resources to a particular project in perpetuity. The need for external support is ever-present for the directors of DSS projects, who must balance their commitment to community involvement with an appreciation of the agendas of external agencies.

The DSS is, in conclusion, a way of doing research that produces high quality data about populations precisely because it embeds within itself a continuous circulation of multiple knowledges. The DSS is certainly not a panacea. Our description has indicated several occasions on which divergent community interests and disagreements about values and priorities seem to impede the orderly flow of knowledge. However, the flows and the obstacles are more visible and particular knowledges are not automatically privileged. This, we argue, has important implications for conducting population research in a climate of declinining research funding. Not only can the data collection occur in a manner that is equitable and ethical but the data collected is likely to be of high quality and appropriate to answer some of the most pressing questions facing countries in Africa and the developing world.

\section{Acknowledgements}

An earlier version of this paper was prepared for the IUSSP Committee on Anthropological Demography Seminar on the Production and Circulation of Population Knowledge, Brown University, March 21-24, 2001. The authors are grateful for comments and suggestions from Anthony Carter, Susan Watkins and the participants in the seminar. 


\section{References}

Caldwell, John C. and Pat Caldwell. 1992. "What Does the Matlab Fertility Experience Really Show?" Studies in Family Planning 23(5): 292-310.

Chambers, Robert. 1996. "Participatory Rural Appraisal and the Reversal of Power." Cambridge Anthropology 19(1): 5-23.

Das Gupta, Monica, Peter Aaby, Michel Garenne and Gilles Pison (eds.). 1997. Prospective Community Studies in Developing Countries. Oxford: Clarendon Press.

Emmett, Tony. 2000. "Beyond Community Participation? Alternative Routes to Civil Engagement and Development in South Africa." Development Studies 17 (4): 501-518.

Garenne, Michel, Stephen Tollman and Kathy Kahn. 2000. "Premarital Fertility in Rural South Africa: A Challenge to Existing Population Policy." Studies in Family Planning 31 (1): 47-54.

Kahn, Kathy and Stephen Tollman. 1998. The INDEPTH network: A comparative perspective on field sites in Africa, Asia, Latin America, and the Middle East. Monograph available from the INDEPTH secretariat, Navrongo Health Research Centre, Accra, Ghana, and the Department of Community Health, University of the Witwatersrand, Johannesburg, South Africa.

Kretzman, John P. and John L. McKnight. 1993. Building Communities from the Inside Out: A Path Towards Finding and Mobilizing a Community's Assets. Evanston, Ill: Center for Urban Affairs and Policy Research.

Lupton, Deborah. 1999. Risk. London: Routledge Press.

MacLeod, Catriona T., Thulani C.Masilela and Elizabeth Malomane. 1998. "Feedback of Research Results: Reflections from a Community-Based Mental Health Program." South African Journal of Psychology 28(4): 215-221.

Moser, Caroline. 1993. Gender Planning and Development: Theory, Practice and Training. New York: Routledge.

Niehaus, Isak. 2001. Witchcraft, Power and Politics: Exploring the Occult in the South African Lowveld. Cape Town: David Phillip.

Ramutsindela, Manno F. and David Simon. 1999. "The Politics of Territory and Place in Post-Apartheid South Africa: The Disputed Area of Bushbuckridge." Journal of Southern African Studies 25(3): 479-498. 
Speigel, Andrew. (1987). "Dispersing Dependents: A Response to the Exigencies of Labour Migration in Rural Transkei." In J. Eades (ed.) Migrants, Workers and the Social Order. London: Tavistock Publications, 113-129.

Tollman, Stephen, Kathleen Kahn, Michel Garenne and John S. Gear. 1999. "Reversal in mortality trends: Evidence from the Agincourt field site, South Africa, 19921995." AIDS 13: 1091-1097.

Tollman, Stephen, Sidney Kark and Emily Kark. 1997. "The Pholela Health Centre: Understanding Health and Disease in South Africa through CommunityOriented Primary Care.” In M. Das Gupta, M. Garenne and G. Pison (eds). Prospective Community Studies in Developing Countries. Oxford: Clarendon Press, 213-232.

Tollman, Stephen, Kobus Herbst and Michel Garenne. 1995. The Agincourt Demographic and Health Study: Phase I. Johannesburg: University of the Witwatersrand, Department of Community Health.

Townsend, Nicholas. 1997. "Reproduction in Anthropology and Demography." In D. Kertzer and T. Fricke (eds.) Anthropological Demography: Towards a New Synthesis. Chicago: The University of Chicago Press.

Townsend, Nicholas, Sangeetha Madhavan and Anita Garey. 2006. "Father Presence in Rural South Africa: Historical Changes and Life-Course Patterns." International Journal of Sociology of the Family 32(2): 173-190. 
Madhavan et al.: Long term community involvement and population knowledge 